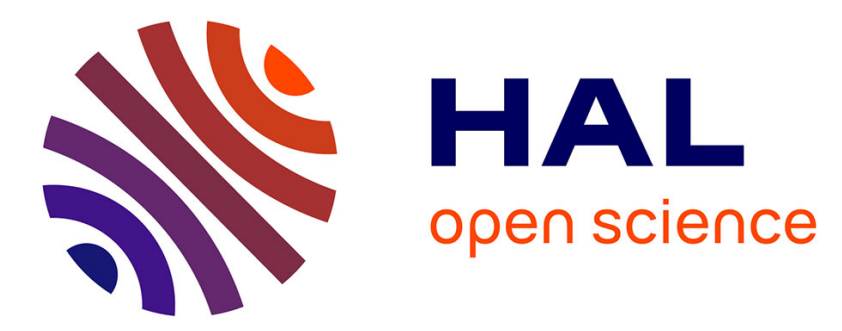

\title{
Flying phase mask for the printing of long submicron-period stitchingless gratings
}

\author{
E. Gamet, Y. Jourlin, S. Pelissier, R. Min, S. Reynaud, C. Veillas, J.-C. \\ Pommier, O. Parriaux
}

\section{- To cite this version:}

E. Gamet, Y. Jourlin, S. Pelissier, R. Min, S. Reynaud, et al.. Flying phase mask for the printing of long submicron-period stitchingless gratings. Microelectronic Engineering, 2006, 83 (4-9), pp.734-737. 10.1016/j.mee.2006.01.002 。 ujm-00358901

\section{HAL Id: ujm-00358901 https://hal-ujm.archives-ouvertes.fr/ujm-00358901}

Submitted on 5 Feb 2009

HAL is a multi-disciplinary open access archive for the deposit and dissemination of scientific research documents, whether they are published or not. The documents may come from teaching and research institutions in France or abroad, or from public or private research centers.
L'archive ouverte pluridisciplinaire HAL, est destinée au dépôt et à la diffusion de documents scientifiques de niveau recherche, publiés ou non, émanant des établissements d'enseignement et de recherche français ou étrangers, des laboratoires publics ou privés. 


\title{
Flying phase mask for the printing of long submicron-period stitchingless gratings
}

\author{
E. Gamet ${ }^{\mathrm{a}}$, Y. Jourlin ${ }^{\mathrm{a},{ }^{*}}$, S. Pelissier ${ }^{\mathrm{b}}$, R. Min ${ }^{\mathrm{a}}$, S. Reynaud ${ }^{\mathrm{a}}$, C. Veillas ${ }^{\mathrm{a}}$, \\ J-C. Pommier ${ }^{\text {a }}$, O.Parriaux ${ }^{\text {a }}$
}

${ }^{a}$ TSI Laboratory UMR CNRS 5516, 18 rue Benoit Lauras, Saint-Etienne 42000, France

Elsevier use only: Received date here; revised date here; accepted date here

\begin{abstract}
Long and stitchingless gratings are printed by means of a read/write head comprising a phase mask illuminated by an intensity modulated laser beam and a reference grating displacement sensor which dictates the modulation period real time. A nearly perfect grating copying is achieved by fixing the sensor grating scale and the written grating substrate on a long platform sliding under the read/write head (c) 2001 Elsevier Science. All rights reserved
\end{abstract}

Keywords : optical lithography; phase mask; stitching; grating ;

\section{Introduction}

With the emergence of diffractive effects for white light processing in flat displays for lossless color separation [1] and lossless polarization [2] the finest feature size of a microstructured surface is imposed by the wavelength of the processed light regardless of the size of the display. It is recognized that light processing down to the blue range imposes grating periods down to just above $100 \mathrm{~nm}$. This represents a big challenge for manufacturing technologies.

The present paper reports on a technique allowing the high productivity printing of large size submicron gratings by means of a small area phase mask illuminated by an intensity modulated laser beam.

Unlike all laser beam pattern generators that write gratings line by line, the present writing scheme prints several thousands lines at a time in a continuous mode without stitching errors. Unlike in a widely used technique for Fibre Bragg Grating writing [3] and in the large grating writing scheme of MIT's Nanoruler [4] the projected interferogramme is not a propagating set of fringes generated by a phase modulator in one of the branches of a Mach-Zehnder, the interferogramme is here static and intensity modulated. This allows more compactness and stability, and does not require a strictly constant displacement velocity of the printed substrate.

\footnotetext{
* Corresponding author. Tel.: +33 (0)4 77915821 ; fax: +33 (0)4 779158 26; e-mail: jourlin@univ-st-etienne.fr
} 


\section{Principle}

the position reference sensor scale by a flexible interface electronics without the need of velocity control.

The principle of the technique is shown fig. 1 .

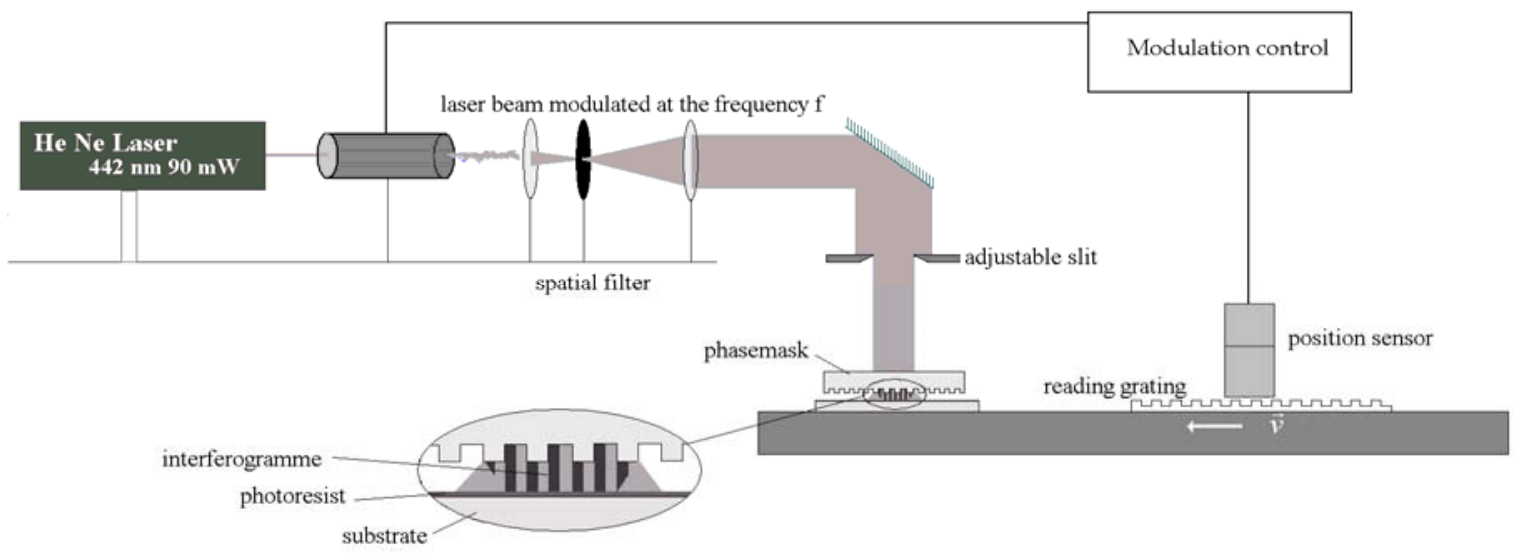

Fig. 1. Optical set up of the write on the fly technique

A photoresist spin-coated substrate is placed on a translation bench. The substrate is UV-exposed through a phase mask maintained at short and constant distance so that the two interfering diffraction orders have good spatial overlap on the resist layer. The exposure source is a He-Cd laser whose beam is modulated, filtered and enlarged. The fixed support of the writing head also holds a diffractive interferometric sensor. It is a massive steel piece fixed to the body of a heavy cast iron bench. The translation stage of the bench is a $500 \mathrm{~mm}$ long steel plate carrying a reference grating scale and the resist coated scale to be printed. Modulating the interferogramme power permits a continuous writing of the grating regardless of the translation velocity : the modulator is driven by the signal delivered by the position sensor. The width of the adjustable slit depends on the exposure conditions i.e. the power of the source and the translation velocity of the bench.

The advantages of the proposed technique are compactness, thus low vibration sensitivity, balanced and very short optical path lengths, thus no sensitivity on the fluctuations of the refractive index of air. Moreover a blue or UV LED can possibly be used as the light source. Amplitude modulation can be adapted to give a large variety of grating groove profiles, and just needs to be locked to the signal of

\section{Interference pattern generation}

The interferogramme needed for the grating printing is produced by a phase mask . In the present case this device is a simple transmission grating etched in a quartz substrate. The groove depth is optimized for maximizing the diffraction efficiency in TE polarization of two interfering diffraction orders. The overlap of the two resulting beams leads to an interference pattern under the mask. The phase mask can be used under normal or oblique incidence. In both cases, the resulting interferogramme period is wavelength independent, thus an illuminating source of broad spectral width can be used.

Ideally case, a phase mask of period $\Lambda$ operating under normal incidence [5] should diffract only in the $+/-1$ orders as shown in figure 2. The resulting interference pattern period is $\Lambda / 2$. This means that a 244 or $248 \mathrm{~nm}$ or even a $193 \mathrm{~nm}$ wavelength light beam with a $280 \mathrm{~nm}$ period phase mask can print the much wanted $140 \mathrm{~nm}$ period (70 nm CD) of a lossless broadband polarizer. 


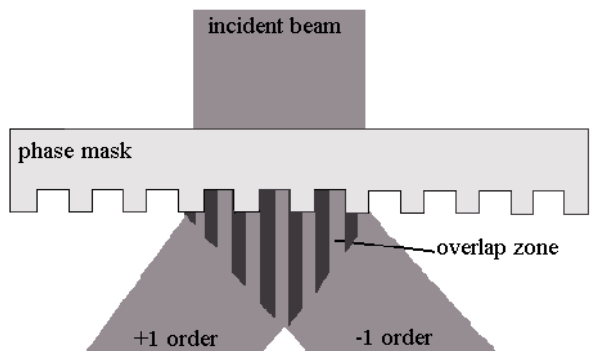

Fig. 2. Phase mask used under normal incidence. The resulting interferogramme period is half of that of the mask.

Under an oblique incidence [6] corresponding to the $-1^{\text {st }}$ order Littrow condition, and for a small diffraction angle, the resulting interferogramme period is the same as the that of the mask. Such exposure scheme can be useful when the scalar electromagnetic field approximation doesn't hold (the zero $^{\text {th }}$ order can't be cancelled) or when the contribution of other orders can't be neglected.

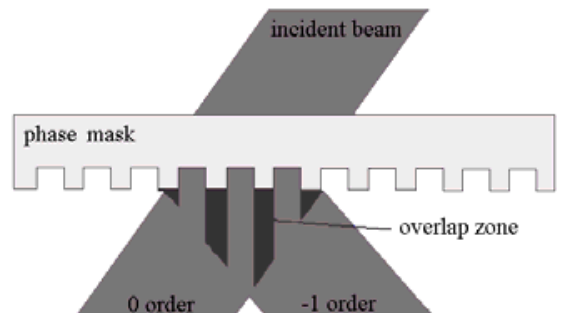

Fig. 3. Phase mask used in oblique incidence. The resulting interferogramme period is the same as the mask grating's.

\section{Amplitude modulation control}

The substrate translates below the phase mask at a speed of approximately $1 \mathrm{~mm} \cdot \mathrm{s}^{-1}$ and its relative position to the phase mask is given by an optical encoder which reads the reference scale. The incremental optical encoder comprises an optical read head consisting of a readout grating, at least two detectors and a laser diode $[7,8]$. The reference scale is a grating of $1 \mu \mathrm{m}$ period. The measurement principle is the well known diffractive interferometry scheme whereby the phaseshift between the orders diffracted by the grating scale is proportional to the relative displacement between the readout and the scale gratings. The optical phase difference between the two diffracted orders is proportional to the displacement and is equal to $2 K_{g} \Delta x$, where $K_{g}$ is the scale grating constant $\left(K_{q}=2 \pi / \Lambda\right)$ and $\Delta x$ is the relative displacement between the scale and the read head. In the present case, the scheme uses a grating scale of $1 \mu \mathrm{m}$ period which diffracts the normally incident beam having crossed the readout grating without diffraction into two phaseshifted diffracted waves. These are then recombined by the readout grating of $0.5 \mu \mathrm{m}$ period which directs the two interference products towards four detectors : there are two phase shifted grating zones in the readout grating so as to have sine and cosine functions of the displacement $\Delta x$.

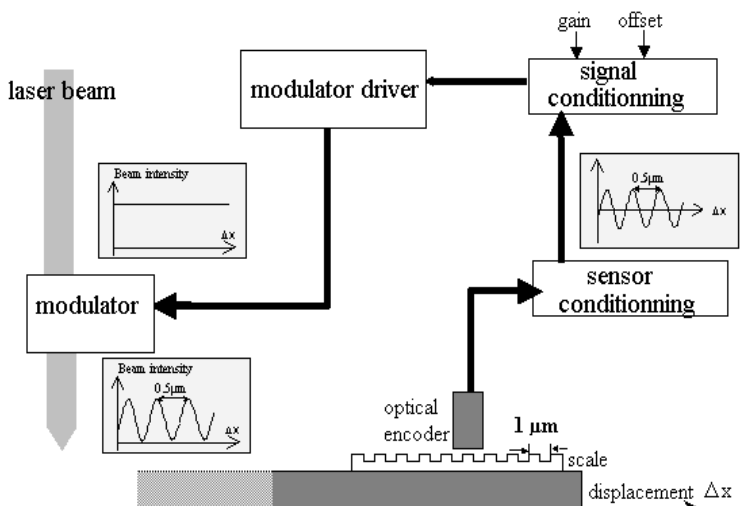

Fig. 4. Exposure beam intensity control loop

The period of the electrical signals corresponds to a relative translation between the readhead and the scale of $0.5 \mu \mathrm{m}$. As the interference product concerns only two orders, the signal is perfectly sinusoidal. This sensor signal is then used in the feedback loop of the laser beam amplitude modulation. For the writing of $0.5 \mu \mathrm{m}$ period gratings, the temporal period of the amplitude modulation is the same of the one of the optical encoder. The current experimental set-up can easily write larger periods such as 1, 2, 4 or $8 \mu \mathrm{m}$, by using the same grating sensor and dividing its signal frequency by $2,4,8$ or 16 respectively; this can be achieved electronically using standard JK flip-flops and a sinus waveform generator integrated circuit.

The modulator is driven by a modulator driver box, which is a high voltage and analog amplifier, capable of delivering more than $800 \mathrm{~V}$ peak to peak output. The gain of the modulator driver is $200 \mathrm{~V} / \mathrm{V}$, which enables a low voltage input drive. The sensor signal is first calibrated in amplitude and offset before being sent to the modulator driver input. As the period of the modulator control signal and the electrical period of the optical encoder are presently 
the same $(0.5 \mu \mathrm{m})$, there is no need of any multiplication therefore the encoder signal is then directly send to the modulator driver.

In so doing, whatever the period ratio between the reference and copied gratings, and whatever the relative translation speed, each copied grating period will get the same total dose.

\section{Experimental steps}

\subsection{Phase mask fabrication}

The phase mask is a $500 \mathrm{~nm}$ period quartz grating optimized for operating in 0/-1 configuration. It was made by holographic exposure of a photoresist (Shipley SPR 505 A) layer. After development the grating was etched by RIBE (Reactive Ion Beam Etching) to the desired depth, i.e. $490 \mathrm{~nm}$. Then the profile is checked by Atomic Force Microscope (AFM) and diffraction efficiencies are controlled optically.

\section{2. "On the fly" exposure process}

The "on the fly" exposure was made on a spin coated photoresist layer of $300 \mathrm{~nm}$ thickness on a $100 \times 100 \mathrm{~mm}^{2}$ glass plate . The angle of incidence was $22^{\circ}$ which provided the highest interference contrast. The $-1^{\text {st }}$ order Littrow is $\arcsin (\lambda / 2 \Lambda)$. The incident beam divergence, the parallelism between the substrate and the mask were controlled to avoid the parasitic fringes formation in the resist layer. The exposure dose control was adjusted by three parameters: the output power of the laser $(90 \mathrm{~mW})$, the slit width $(1 \mathrm{~mm})$ and the velocity of the translation bench $\left(1 \mathrm{~mm} \cdot \mathrm{s}^{-1}\right)$.

\subsection{Results}

The obtained $100 \mathrm{~mm}$ long gratings are sinusoidal with a period of $500 \mathrm{~nm}$ as shown figure 5 . The groove depth is about $250 \mathrm{~nm}$. The period uniformity along the grating track is likely to be very good as the reference grating scale is corrected. It will later be tested using a differential dual-sensor scheme allowing the determination of period variations to better than one picometer [9]. The groove profile uniformity is good along the grating track; it is presently non uniform along the grating lines since the beam is essentially Gaussian. An improvement will be provided by giving the exposure beam a top hat profile in the direction normal to the grating track.

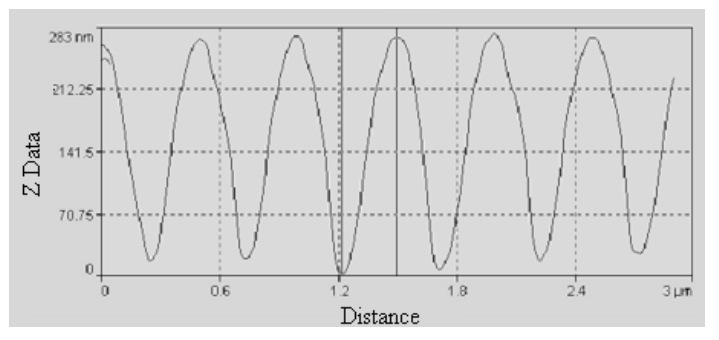

Fig. 5. AFM profile of a resist grating

\section{Conclusion}

In conclusion, the experimental results demonstrate the feasibility of an amplitude modulated phase mask continuous writing technique over a length which can now be easily extended to $500 \mathrm{~mm}$ and over. The present development is towards the measurement of the spatial frequency characteristics and a beam shaping for more uniform exposure.

\section{References}

[1] G. A. Schiavone, K. O'Neill , K. D. Paulsen, Journal of the Opt. Soc. of America A, Opt. and Image Science, vol. 14 , no 9 , pp. $2212-2222$ (1997).

[2] D. P. Hansen, J. Gunther, Moxtek, Patent No.: US 6,452,724.

[3] Alcatel, Patent No. FR 2768819 - A1.

[4] G.C. Chen, P.T. Konkola, R.K. Heilmann, C. Joo and M.L. Schattenburg, Proc. SPIE 4936, Nano- and Microtechnology: Materials, Processes, Packaging, and Systems, pp. 126-134 (2003).

[5] K. O. Hill, B. Malo, F. Bilodeau, D. C. Johnson, and J. Albert, Appl. Phys. Lett., vol. 62, no. 10, pp. 1035-1037 (1993)

[6] O.Parriaux, H. Vuilliomenet, P. Sixt, N.Cuny, Optical Engineering, vol. 34, no 9 , pp. 2657-2659 (1995)

[7] Y. Jourlin, PhD Thesis (2000).

[8] G. Voirin, U. Benner, F. Clube , Y. Darbellay, O. Parriaux , S. Schneider and P. Sixt, Proceedings of SPIE, 3099, pp. 166175 (1997).

[9] Y. Jourlin, J. Jay, F. Pigeon, G. Bouchet, O. Parriaux, P. van Dijk, R. Pellens, S. Topçu, Y. Alayli and M. Bonis., Microelectronic Engineering , Vol.61-62, 2002, pp. 11011106 (2002) 